\title{
PENERAPAN METODE CFC (CONTINUOUS FLOW CASTING) PADA PERBAIKAN KOMPONEN YANG TERBUAT DARI PADUAN ALUMINIUM
}

\author{
Muki Satya Permana, Edho Prakoso dan Muhammad Iqbal Taufani \\ Program Studi Teknik Mesin Fakuktas Teknik Universitas Pasundan \\ e-mail: mkpermana@yahoo.com/muki.satya@unpas.ac.id
}

\begin{abstract}
Many automotive components are made of Aluminum alloy. The broken or cracked components are generally replaced with a new product. For the reason of the number of component and cost, recondition is considered as a very profitable solution. So far, the recondition on this alloy component was repaired by using TIG or MIG. However, this alloy is easily oxidized and forms Aluminum oxide. In addition, the alloy is also easy to form a fine cavity and weld cracking. So, the problem to be solved in this work is how to conduct the CFC (Continuous Flow Casting) process so that the repair process produces a joining that is free from cavities and hot cracks. In this work, the objective is to repair an aluminum alloy by using the CFC method. The problem solution is performed by experimental investigation, which is the repair process using CFCs. The surface repairs result was poured by dye penetrant fluid then metallographic examination and hardness testing. From the experimental results obtained that the metallurgical bonding in the connection area is considered good because there is continuity of micro structure between the parent metal and filler metal.
\end{abstract}

Keywords: Recondition, Continuous Flow Casting, metallographic observation, metallurgical bonding.

\section{PENDAHULUAN}

Telah banyak upaya yang dilakukan industri untuk melakukan penghematan biaya produksi. Di bidang manufaktur khususnya, penghematan dilakukan dengan cara memperbaiki komponenkomponen yang patah atau retak pada saat dibuat dengan proses pengecoran maupun pada saat pemakaian. Dengan pertimbangan harga terlebih lagi jika itu produk impor, biasanya komponen yang rusak diperbaiki (repair/rekondisi). Lebih dari itu, volume komponen yang sangat besar dan tingginya harga komponen maka proses perbaikan mulai dipandang sebagai solusi yang sangat menguntungkan.

Pada awalnya komponen-komponen yang patah atau retak diperbaiki dengan menggunakan proses pengelasan TIG atau MIG [1-3]. Namun logam ini mudah teroksidasi dan membentuk oksida Aluminium $\mathrm{Al}_{2} \mathrm{O}_{3}$. Terlebih lagi, pengelasan pada paduan ini mudah terjadi rongga halus maupun retak las. Salah satu metode perbaikan yang telah dikembangkan pada logam besi cor yaitu metode TFC (Turbulence Flow Casting) ternyata tidak memberikan hasil yang memuaskan apabila diterapkan ada paduan Aluminum [4-10]. Terdapat metode perbaikan lain yaitu Ultrasonic Insert Casting namun metode ini masih memiliki kelemahan karena tidak mudah diterapkan di lapangan, relatif mahal dan dimensi cacat yang dapat diperbaiki relatif kecil [11].

Untuk meminimalisir masalah tersebut maka dalam penelitian ini telah dikembangkan metode baru yaitu dengan memanfaatkan proses pengecoran yang dikenal dengan metode CFC (Continuous Flow Casting) dan telah disempurnakan dengan menggunakan bantuan gas Argon. Oleh sebab itu, penelitian ini mengetengahkan masalah bagaimana mengembangkan dan menerapkan metode CFC dalam memperbaiki cacat permukaan dengan proses pengecoran sehingga memiliki kualitas sambungan dan sifat-sifat yang sesuai dengan logam induk. Tujuan yang ingin dicapai dalam penelitian ini adalah melakukan eksperimen proses perbaikan cacat permukaan dengan menggunakan metode CFC dan melakukan optimasi parameter-parameter yang berpengaruh terhadap keberhasilan proses perbaikan terhadap kualitas sambungan dari komponen yang diperbaiki.

Penyelesaian masalah dilakukan melalui kaji ekperimental. Eksperimen dilakukan dengan menggunakan dua tipe proses CFC yaitu metode Cetakan Tertutup (Closed Mold) dan Cetakan Terbuka (Open Mold). Metode ini dikembangkan, diterapkan dan dibantu dengan cara mengalirkan gas argon selama proses berlangsung untuk melindungi permukaan yang diperbaiki agar tidak 
terbentuk rongga maupun retak las. Pencarian solusi atas masalah ini akan dilakukan dan diterapkan pada paduan $\mathrm{Al}-12 \% \mathrm{Si}$ sebagai bahan kajian. Hasil perbaikan akan diperiksa dengan menggunakan pengamatan metalografi [12] yaitu untuk melihat kesamaan struktur dan kualitas sambungan antara logam induk dengan logam pengisi dan pengujian kekerasan.

\section{METODE PENELITIAN} berikut:

Tahapan pernyiapan dan proses perbaikan serta sejumlah pengamatan disusun sebagai

- Penyiapan spesimen Al-12\%Si berukuran $100 \mathrm{~mm}$ x $30 \mathrm{~mm}$ x $30 \mathrm{~mm}$. Bentuk cacat berupa alur U berukuran 10 mm x 10 mm (Gambar 1a)

- Penyiapan cetakan CFC Open Mold (Gambar 1b) dan CFC Closed Mold (Gambar 1c).

- Proses penuangan dilakukan secara kontinu untuk selang waktu tertentu.

- Pengaturan beberapa parameter yaitu temperatur penuangan logam cair, temperatur preheat, dan waktu penuangan.

- Pemeriksaan cacat permukaan dengan menggunakan metode dye penetrant

- Pengamatan metalografi.

- Pengujian kekerasan.

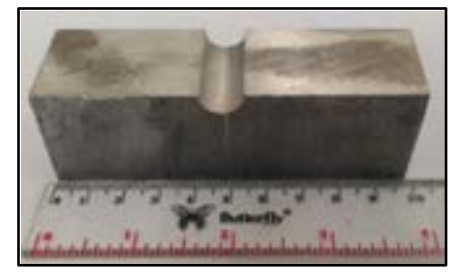

(a)

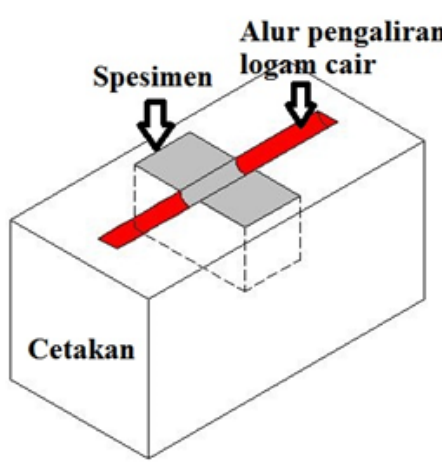

(b)

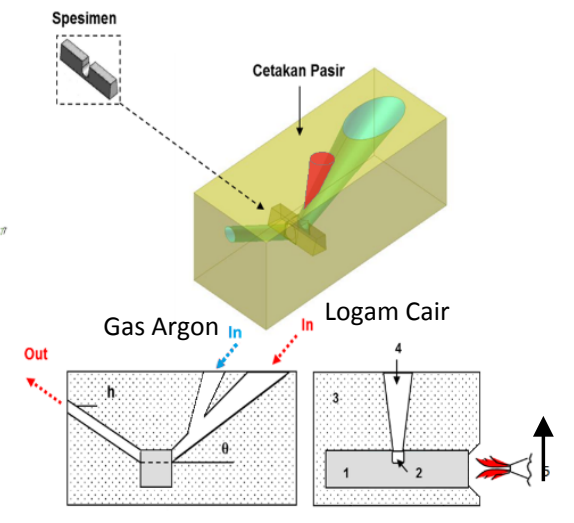

(c)
Flame

Gambar 1. (a). Gambar spesimen, (b). CFC Open Mold dan (c). CFC Closed Mold

\section{HASIL DAN PEMBAHASAN}

Kegagalan proses perbaikan yang sering terjadi adalah logam pengisi nampak seperti tersambung (Gambar 2a dan Gambar 2b). Namun saat pemotongan saluran logam pengisi dilakukan, ternyata logam pengisi terlepas dari logam induk (Gambar 2c). Kegagalan penyambungan ini diakibatkan karena temperatur penuangan logam cair terlalu rendah yaitu dibawah $900^{\circ} \mathrm{C}$. Kegagalan lain adalah logam tersambung namun terdapat banyak porositas dan rongga di area sambungan. Ketidaksempurnaan ini disebabkan karena logam cair yang dituangkan ke permukaan cacat bereaksi dengan udara sekitar dan terbawa ke permukaan cacat pada saat proses penyambungan berlangsung (Gambar 3).

Hasil perbaikan yang dinyatakan berhasil dan hampir terbebas dari porositas diperlihatkan pada Gambar 5. Hasil perbaikan yang ditunjukkan pada Gambar 4 adalah hasil perbaikan dengan menggunakan CFC Open Mold. Walaupun cara ini dinyatakan telah berhasil dalam memperbaiki cacat permukaan namun masih terdapat porositas di sekitar sambungan. Hasil perbaikan yang lebih sempurna dilakukan dengan menggunakan CFC Closed Mold (Gambar 5). Rangkuman seluruh hasil perbaikan disajikan pada Tabel 1. Proses perbaikan yang dinyatakan berhasil adalah pada poin 9 dan 10. Dari hasil percobaan tersebut dapat diketahui bahwa faktor utama yang menentukan keberhasilan proses penyambungan adalah harga temperatur penuangan logam cair ke dalam cetakan. Dalam percobaan ini, temperatur penuangan harus berada diatas $915^{\circ} \mathrm{C}$. Selanjutnya, agar sambungan 
terhindar dari porositas dan cacat rongga maka saat perbaikan dialirkan gas argon sebanyak 10 liter per menit. Gambar 4 menunjukkan spesimen hasil perbaikan dan interface hasil penyambungan. Dari Gambar 4, secara visual tidak nampak adanya batas pertemuan antara logam induk dengan logam pengisi. Hal ini menunjukkan bahwa logam spesimen yang telah diperbaiki dengan metode ini seolah-olah tidak mengalami proses perbaikan. Struktur mikro di logam induk dan di logam pengisipun memiliki kesamaan struktur, sebagaimana diperlihatkan pada Gambar 4 dan Gambar 5. Dengan demikian maka apabila metode ini diterapkan pada komponen komersial maka komponen tersebut nampak seperti baru seperti belum pernah mengalami perbaikan. Gambar 5 menunjukkan spesimen hasil perbaikan dan memperlihatkan interface hasil penyambungan dengan menggunakan teknik di poin 10 pada Tabel 1. Secara visual, tampak area logam pengisi berbeda dengan logam induk. Perbaikan dengan cara yang terakhir menghasilkan kualitas logam pengisi yang lebih baik karena hampir tidak ada porositas sebagaimana pada logam induk. Dengan demikian maka teknik perbaikan yang terakhir ini dinyatakan sebagai proses perbaikan dengan metode CFC Closed Mold yang dianggap paling sempurna.
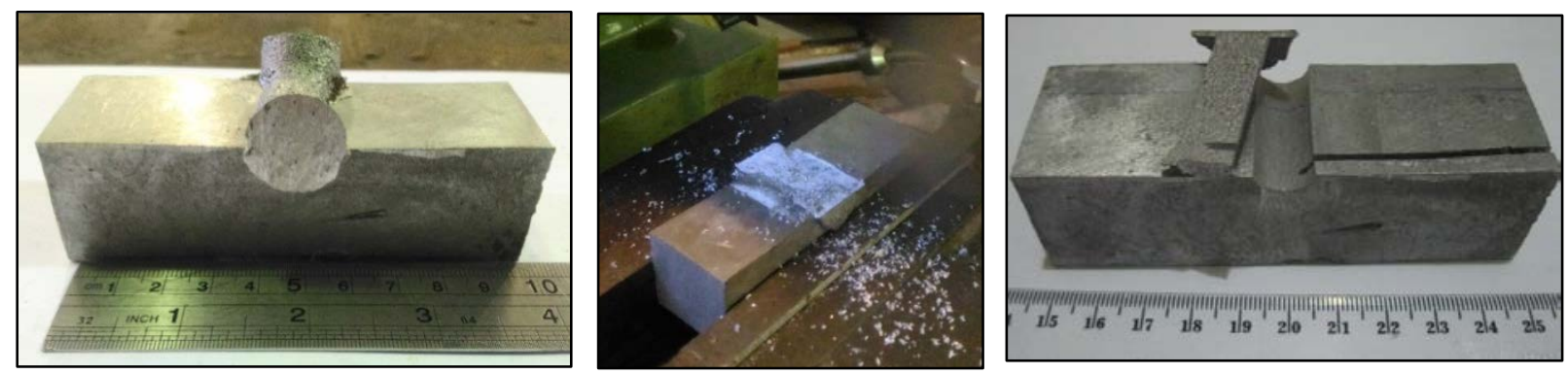

Gambar 2. (a). Hasil perbaikan, (b). pemotongan saluran logam pengisi dan (c). logam pengisi lepas

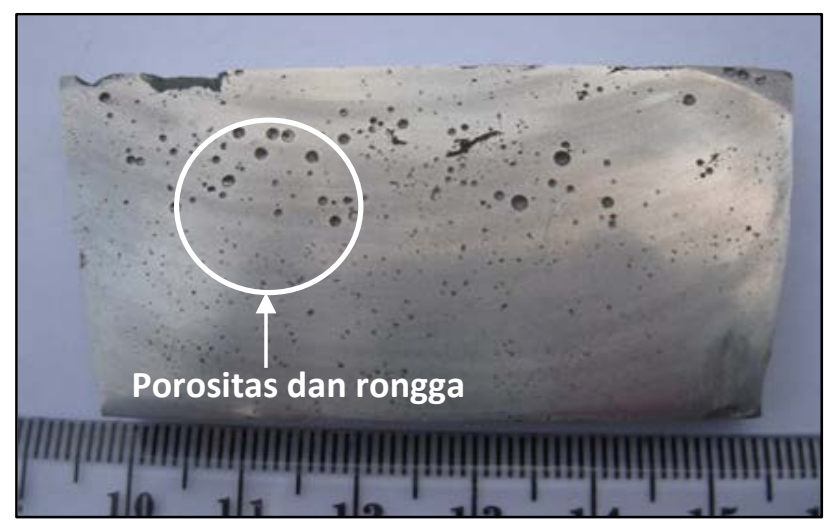

Gambar 3. Porositas dan rongga pada spesimen hasil perbaikan
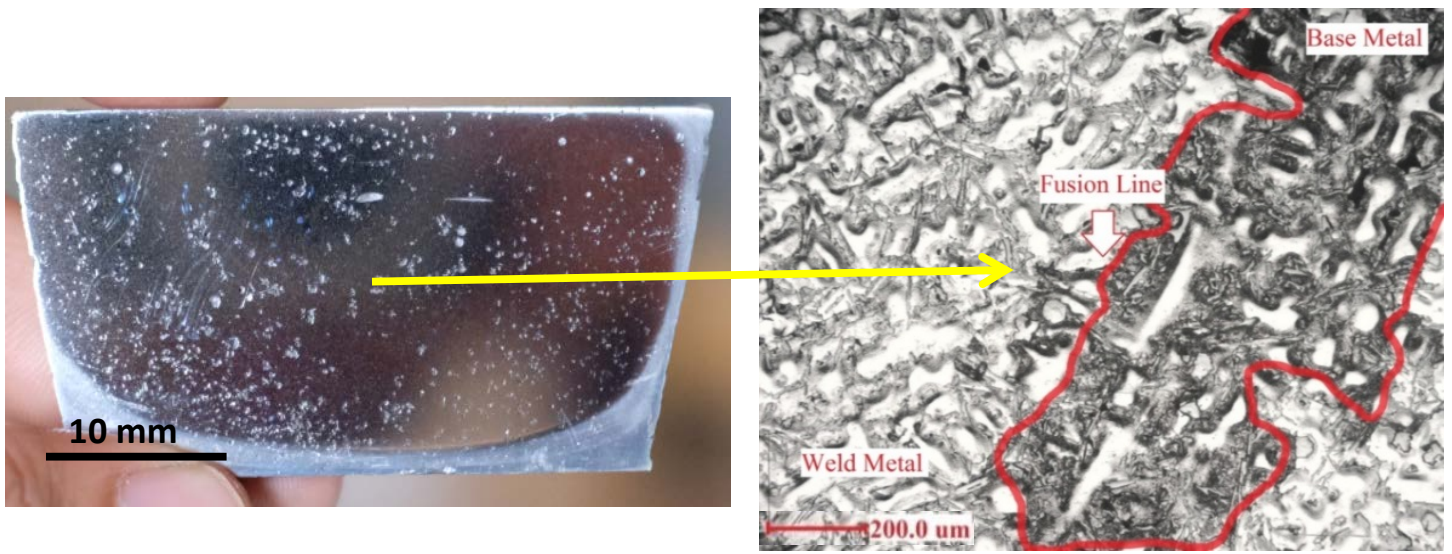

Gambar 4. Permukaan spesimen hasil perbaikan dengan menggunakan metode CFC Closed Mold dan struktur mikro (Hasil poin 10 di Tabel 1) 
Tabel 1. Rangkuman hasil eksperimen dengan menggunakan metode CFC

\begin{tabular}{|c|c|c|c|c|}
\hline No. & Spesimen & Teknik Perbaikan & Parameter & Hasil \\
\hline 1. & $\begin{array}{l}\text { Pre-Trial, pada berbagai dimensi } \\
\text { spesimen dan ukuran cacat }\end{array}$ & TFC - Cup \& Drag & $\begin{array}{l}\text { Berbagai parameter } \mathrm{t} \\
\text { Tp, Tpr }\end{array}$ & Tidak tersambung \\
\hline 2. & $\begin{array}{l}100 \mathrm{~mm} \text { x } 25 \text { mm x } 10 \text { mm, } \\
\text { Dimensi Cacat: } 10 \text { mm x } 10 \text { mm }\end{array}$ & TFC - Cup \& Drag & $\begin{array}{l}\mathrm{t}=2 \text { detik, } \mathrm{Tp}=750^{\circ} \mathrm{C} \\
\mathrm{Tpr}=200\end{array}$ & Tidak tersambung \\
\hline 3. & $\begin{array}{l}100 \mathrm{~mm} \text { x } 30 \mathrm{~mm} \text { x } 30 \text { mm, } \\
\text { Dimensi Cacat: } 10 \text { mm x } 10 \mathrm{~mm}\end{array}$ & TFC - Cup \& Drag & $\begin{array}{l}\mathrm{t}=3 \text { detik, } \mathrm{Tp}=750^{\circ} \mathrm{C} \\
\mathrm{Tpr}=200^{\circ} \mathrm{C}\end{array}$ & Tidak tersambung \\
\hline 4. & Idem & TFC - Drag & $\begin{array}{l}\mathrm{t}=5 \text { detik, } \mathrm{Tp}=750^{\circ} \mathrm{C} \\
\mathrm{Tpr}=200^{\circ} \mathrm{C}\end{array}$ & $\begin{array}{l}\text { Tersambung, } \\
\text { Incomplete } \\
\text { fusion, porositas }\end{array}$ \\
\hline 5. & Idem & TFC - Drag & $\begin{array}{l}\mathrm{t}=10 \text { detik, } \mathrm{Tp}= \\
750^{\circ} \mathrm{C}, \mathrm{Tpr}=200^{\circ} \mathrm{C}\end{array}$ & $\begin{array}{l}\text { Tersambung, } \\
\text { Incomplete } \\
\text { fusion, porositas }\end{array}$ \\
\hline 6. & Idem & TFC - Drag + Stopper & $\begin{array}{l}\mathrm{t}=15 \text { detik, } \mathrm{Tp}= \\
750^{\circ} \mathrm{C}, \mathrm{Tpr}=200^{\circ} \mathrm{C}\end{array}$ & $\begin{array}{l}\text { Tersambung, } \\
\text { porositas }\end{array}$ \\
\hline 7. & Idem & $\begin{array}{l}\text { TFC - Drag + Stopper, } \\
\text { Inert Gas Argon }\end{array}$ & $\mathrm{Tp}=617^{\circ} \mathrm{C}$ & Tidak tersambung \\
\hline 8. & Idem & $\begin{array}{l}\text { TFC - Drag + Cup, } \\
\text { Stopper, Inert Gas } \\
\text { Argon }\end{array}$ & $\mathrm{Tp}=690^{\circ} \mathrm{C}$ & Tidak tersambung \\
\hline 9. & Idem & $\begin{array}{l}\text { CFC - Drag + Stopper, } \\
\text { Inert Gas Argon }\end{array}$ & $\mathrm{t}=30$ detik, $\mathrm{Tp}=915^{\circ} \mathrm{C}$ & $\begin{array}{l}\text { Berhasil } \\
\text { Tersambung }\end{array}$ \\
\hline 10. & Idem & $\begin{array}{l}\text { CFC - Drag + Cup, } \\
\text { Stopper, Inert Gas } \\
\text { Argon }\end{array}$ & $\mathrm{t}=10$ detik, $\mathrm{Tp}=956^{\circ} \mathrm{C}$ & $\begin{array}{l}\text { Berhasil } \\
\text { Tersambung }\end{array}$ \\
\hline
\end{tabular}
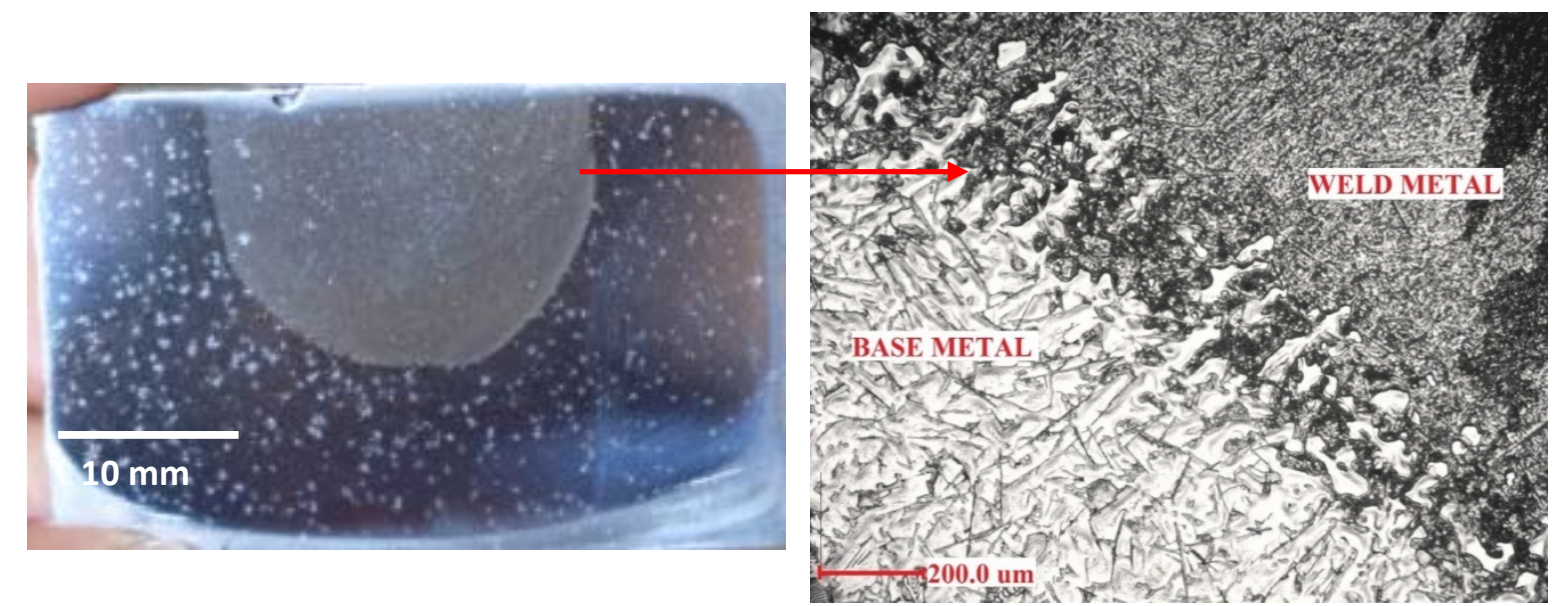

Gambar 5. Permukaan spesimen hasil perbaikan dengan menggunakan metode CFC Closed Mold dan struktur mikro (Hasil poin 10 di Tabel 1)

Dari hasil pengujian kekerasan dengan menggunakan metode Vickers diperoleh bahwa harga kekerasan di logam pengisi memiliki harga yang relatif lebih besar dibandingkan dengan logam induk. Perbedaan kekerasan antara logam pengisi dengan logam induk untuk metode CFC Open Mold dan CFC Closed Mold berturut-turut adalah 16\% dan 24\%. Harga kekerasan hasil pengujian ini ditunjukkan pada Gambar 6. 


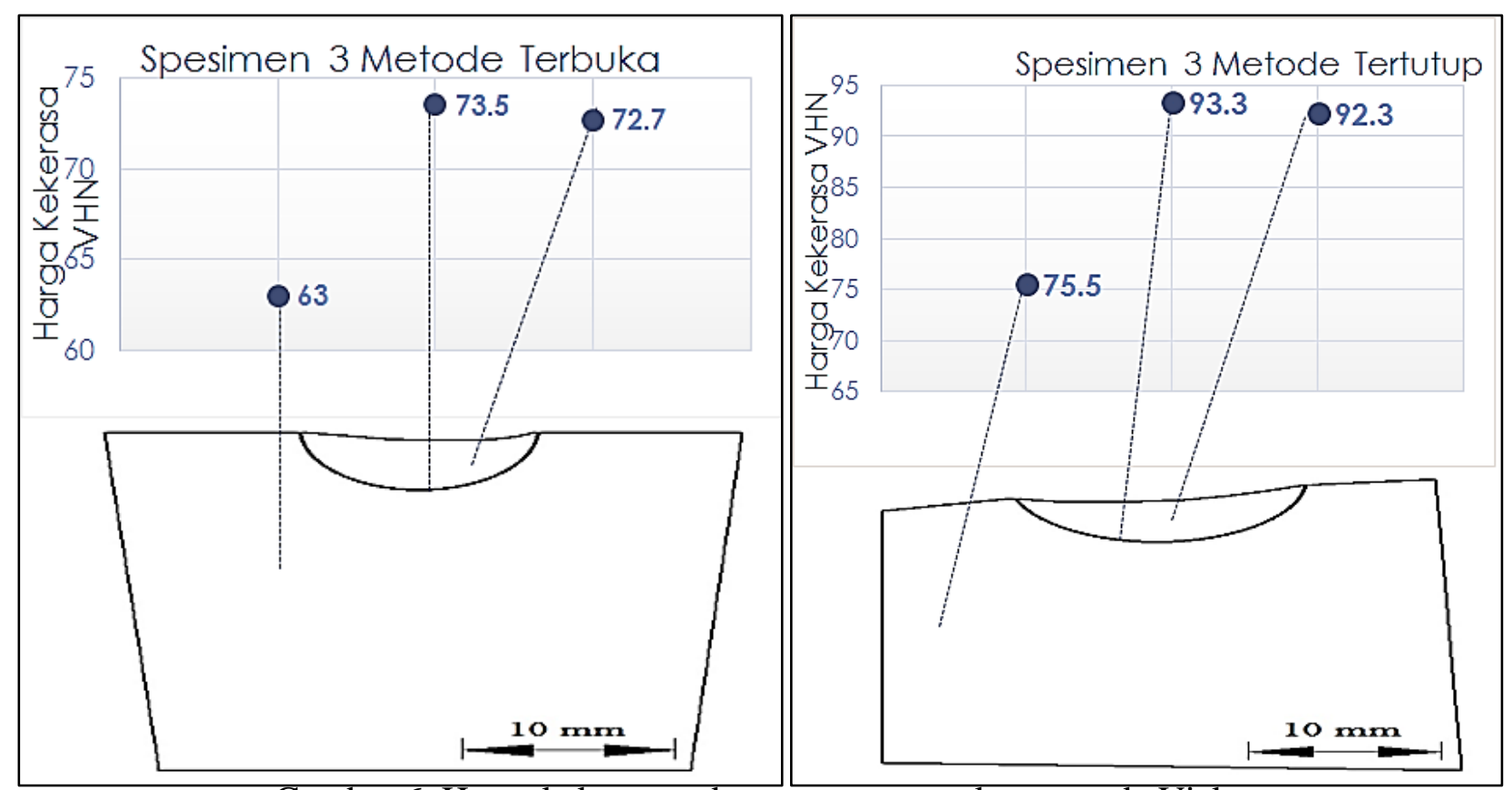

Gambar 6. Harga kekerasan dengan menggunakan metode Vickers

\section{SIMPULAN}

Beberapa hal yang dapat disimpulkan dari hasil penelitian ini adalah: 1). Teknik perbaikan dengan menggunakan metode CFC Open Mold dan CFC Closed Mold dinyatakan berhasil dalam memperbaiki komponen yang terbuat dari paduan Al-Si. 2) Perbaikan dengan menggunakan $C F C$ Closed Mold lebih baik dari pada CFC Open Mold. 3) Parameter proses perbaikan meliputi temperatur penuangan minimal $915^{\circ} \mathrm{C}$, waktu penuangan minimal 10 detik, temperatur preheat berkisar $200^{\circ} \mathrm{C}$, dan jarak penuangan logam cair ke spesimen adalah sebesar $100 \mathrm{~mm}$. 4) Harga kekerasan logam induk dengan menggunakan metode Vickers dan perbedaan kekerasan antara logam pengisi dengan logam induk untuk metode CFC Open Mold dan CFC Closed Mold berturutturut adalah 63; 75,5; 16\% dan 24\%. 5) Penggunaan metode CFC memiliki keunggulan yaitu dapat menghasilkan kualitas sambungan yang serupa dengan logam induk. 6) Perbaikan dengan menggunakan metode CFC mampu memperbaiki komponen dalam jumlah banyak pada waktu yang hampir bersamaan dengan durasi proses yang relatif singkat.

\section{DAFTAR PUSTAKA}

[1]. Sindo Kou, 2003, Welding Metallurgy, $2^{\text {nd }}$ Ed, John Wiley \& Sons, Inc. Publication.

[2]. Harsono Wiryosumarto, Toshie Okumura, Teknologi Pengelasan Logam, PT Pradnya Paramita, 2000.

[3]. http://id.wikihow.com/Mengelas-Alumunium, diturunkan pada bulan Agustus Tahun 2016.

[4]. Muki S. Permana, Rochim Suratman, Budi H. Setiamarga, Bukti Tarigan, 2012, The Application of New Method in Gray Cast Iron Repair by Turbulence Flow Casting, Seminar Nasional "Efisiensi Energi untuk Peningkatan Daya Saing Industri Manufaktur \& Otomotif Nasional” (SNEEMO) 2012 Politeknik Manufaktur Astra, Jakarta, 27 September 2012.

[5]. Muki Satya Permana, Susan Heryanti, Iqbal Taufani, Edho, 2016, Pengembangan Lanjut Metode Perbaikan Komponen Aluminium Al-Si dengan Menggunakan Metode Turbulence Flow Casting, Seminar Otofest, Universitas Pasundan.

[6]. Muki S. Permana, Susan Heryanti, Ahmad Ulinuha, Sutrisno Yuwono, 2015, Penerapan Metode Turbulence Flow Casting dalam Perbaikan Komponen Otomotif yang Terbuat dari Paduan Aluminium (Studi Kasus: Paduan Al-Si), Prosiding Seminar Nasional ke-2 Rekayasa Material, Sistem Manufaktur dan Energi. 
[7]. Muki S. Permana, Rochim Suratman, Budi H. Setiamarga, Bagus Budiwantoro, 2006, A Newly Developed Method in Repairing Surface Defect for Components of Gray Cast Iron, IMTCE 2006, 5th International Material Conference \& Exhibition, Kuala Lumpur Malaysia.

[8]. Muki S. Permana and Rochim Suratman, 2007, How to Repair Surface Defect of Gray Cast Iron Components Using New Method", The 9th AWF Meeting International Welding Seminar, 23-24 October 2007, Jakarta.

[9]. Muki S. Permana, Rochim Suratman, Budi H. Setiamarga, 2012, Experimental and Numerical Investigation of Melting and Solidification during Gray Cast Iron Repair by Turbulence Flow Casting, International Journal of Mechanical Computational and Manufacturing Research, Vol.1. No.1, 35-41, ISSN: 2301-4148.

[10]. Muki Satya Permana, 2015, Experimental Observation and Analytical Modeling of Melting and Solidification during Aluminum Alloy Repair by Turbulence Flow Casting, International Journal on Smart Material and Mechatronics Vol. 2 No. 2.

[11]. Pan J., Yoshida M., Sasaki G., Fukunaga H., Fujimura H. dan Matsura M., 2000, Ultrasonic Insert Casting of Aluminum Alloy, Scripta Materialia, 43, 155-159.

[12]. ASM Handbook, 2004, Metallography and Microstructures, ASM International, Vol. 9. 